\title{
DE PLAATS VAN DEN CREOOL IN DE LITERATUUR VAN SURINAME
}

DOOR

FRED. OUDSCHANS-DENTZ

De plaats van den creool in de literatuur van Britsch Guyana werd ongeveer vijftien jaren geleden door Rodway behandeld in het thans niet meer bestaande tijdschrift Timehri, en hij kwam tot de gevolgtrekking, dat toen eerst de laatste 25 jaren de creolen een en ander van beteekenis over deze kolonie geschreven hebben.

Hetzelfde verschijnsel doet zich in Suriname voor. Het voornaamste over Suriname is in den loop der eeuwen door Hollanders en Duitschers geschreven, en eerst de laatste 40 jaar is er een groeiende reeks geschriften en publicaties van creolen waar te nemen. De vraag kan dus worden gesteld, of de creool in de toekomst die plaats zal behouden en van meer beteekenis zal doen worden, en ongetwijfeld zal men hierop een bevestigend antwoord kunnen geven.

Te dien einde hebben wij onderzocht, welke Surinamers over land en volk geschreven hebben en welke onderwerpen zij hebben behandeld. Daarbij kozen wij als leiddraad de catalogus van de Koloniale Boekerij te Paramaribo. De arbeid van deze Surinamers strekte zich dan uit over de volgende 8 rubrieken: 1. aardrijkskunde, land- en volkenkunde; 2 . geschiedenis en oudheidkunde; 3. staatkunde en staathuishoudkunde, rechtsgeleerheid en wetgeving, kolonisatie, slavernij en emancipatie; 4. godgeleerdheid, godsdienst en zending; 5 . taal- en letterkunde, onderwijs en opvoeding; 6. geneeskundige wetenschappen; 8 . landbouw, nijverheid, handel en scheepvaart. Daarbij zouden wij de volgende rubrieken willen voegen: Boschnegers en Indianen en Muziek; tezamen dus 10 rubrieken. Bij de namen, welke wij uit voornoemde catalogus opteekenden, hebben wij de sedert 1917 verschenen jaargangen van De West-Indische Gids nagegaan, zoodat wij mogen aannemen, dat vrijwel alle Surinamers in het volgende overzicht zijn genoemd, en mochten wij een hebben overgeslagen, dan houden wij ons voor aanvulling aanbevolen.

Wij vestigen tevens de aandacht erop, dat drie vrouwen in ons overzicht voorkomen, en wel mejuffrouw M. E. L. Vlier, wier ge- 
schiedenis van Suriname eertijds een veel geraadpleegd werkje was; mevrouw A. van Genderen-Rühmann, die een werkje over maisrecepten schreef naar aanleiding van de prijsvraag, door de firma C. Kersten \& Co. te Paramaribo uitgeschreven, en mevrouw Amo-vanSpall, die met stijgend succes verschillende Surinaamsche muziekstukkenvervaardigde; een harer composities,,When dreams come true" werd door het Hollywood Radio Station uitgezonden.

Voorts herinneren wij eraan, dat Lou Lichtveld, die onder den schuilnaam Albert Helman schrijft, een auteur is, wiens werken ver over de grenzen bekendheid verwierven, en onder Nederlands goede literatoren wordt gerekend. Onder de namen treft men verder een Roomsch-katholiek priester aan, nl. pater H. F. Rikken, die tal van boeiende verhalen over geschiedkundige onderwerpen van Suriname heeft geschreven.

In de 1ste rubriek dan die van Aardrijkskunde, Land-en Volkenkunde rangschikken wij (alles in alphabetische volgorde): Abarbanel, J.; Anakram, N.; Azijnman, S. H.; Bartelink, E. J.; Benjamins, dr. H. D.; Bueno Bibaz, J; Bueno de Mesquita, J. A.; Calor, A. T.; Comvalius, Th. C.; Douglas, Chas; Duurvoort, C. A.; Einaar, J. F. E. ; Essed, E.; Eyck-Benjamins, mevr. Nelly van; Ferall, R.A. P. C.O' ; Ferrier, J. H. ; Findlay, D. ; Focke, mr. H. C. ; Heckers, A. A. ; Herdigein, H. D.; Heymans, J. F.; Kuiperbak,B.; Lauriers, L. A.; Lichtveld, Lou; Lier, W. F. van; Lobato, Julius. W.; Loth, W. L.; Marcus, A. W. ; Monkou, J. J. ; Morpurgo, A. J. ; Oostburg, A. M. F.; Penard, A. P.; Penard, F. P.; Penard, Thomas E.; Percival, J. B.; Pool, J. F.; Rikken, pater H. F.; Romondt, W. H. A. van; Samson, A. Ph.; Samson, Ph. A.; Silva, S. da; Simons R. D.; Spalburg, J. G.; Stuger, J. L.; Tafares, J.; Thomson, J. R.; Trikt, F. Th. van; Waaldijk, A. L.; Wesenhagen, mr. A. J.; Wolff, H. J.; Wong, A.

In de 2de rubriek: Geschiedenis en oudheidkunde: Azijnman, S. H.; Bueno de Mesquita, J. A.; Comvalius, Th. C. ; Einaar, J. F. E; Ellis, H. W. R. ; Kom, A. de; Loth, W. L. ; Marcus, A. W. ; Penard, Th.E.; Rier, C. P.; Rikken, H.F.; Samson, Ph. A.; Simons, R. D.; Spalberg, J. G.; Stuger, J. L.; Thomson, J. R. ; Vlier, mejuffrouw M. E. L.; Wolff, H. J.

De 3de rubriek Staat- en Staathuishoudkunde, Rechtsgeleerdheid en Wetgeving, Kolonisatie, Slavernij en Emancipatie: Amson, C. L. G. van; Biswamitre, C. R.; Brandon, H. G.; Bueno Bibaz, S.; Colaço Belmonte, B. E.; Comvalius, Th. C.; Conradi, J. C. M. G.; Coutinho, D.; Dragten A. A.; Fernandes, A. S. J.; Heylidy, H.; Juda, M. ; Kom, A. de; Marcus, Joh. J. ; Mesquita, J. de; Nelson, 
L. E.; Oliviera, A. Th. ; Rellum, J. ; Rier, C. P.; Romondt, W. H. A. en C. G. J. van; Rossum, E. A. van; Samson, Ph. A.; Sanches Dan, J.; Sarucco, J. C.; Simons, R. D.; Sleur, J. R.; Waaldijk, A. L.; Wolff, C. E.; Zaal, G. Ph.; Zeegelaar, F.

De 4de rubriek: Godgeleerdheid, Godsdienst en Zending, Blufpand, J. M.; Doth, R. E. L.; Leerdam, H.; Leerdam, J. M. ; Penard, gebroeders; Rier, C. P.

In de 5de rubriek Taal- en Letterkunde, Onderwijs en Opvoeding vinden een plaats: Benjamins, dr. H. D.; Comvalius, Th. C.; Ferrall, R. A. P. C. O'; Focke, mr. H. C.; Helstone, J. N.; Heymans, J. F.; Lichtveld, Lou; Lobato, Julius W.; Marcus, A. W.; Marcus, Joh. C. ; Morpurgo, A. J.; Morpurgo, G. J.; Ommeren, H J. van; Redmond, Ph. J.; Rellum, Julius; Rikken, pater H. F.; Rier C. P.; Rustwijk, G. G. T.; Sleur, J. R.; Simons, R. D.; Themen, E. A. J.; Thomson, J. R.;

De 6de rubriek is die van de Geneeskundige Wetenschappen. Daarin komen voor: Emanuels, J.; Essed, W. F. R.; Flu, P. C.; Gaander, C. F.; Leerdam, H.; Leerdam, J. M.; Lichtveld, L.; May, G. T.; Nassy, J. F.; Samson, A. Ph.; Simons, Chr. F.; Simons R. D. G. Ph.; Vries, dr. E. de; Wolff, dr. J.

De 7de rubriek Natuurkundige Wetenschappen en fraaie Kunsten is klein. Hierin troffen wij slechts aan de namen van: Benjamins, dr. H. D.; Focke, mr. H. C.; Halfhide, dr. J. J. ; Penard, A. P.; Penard, Thomas E.; Penard, E. P.

De 8ste rubriek is die van Landbouw, Nijverheid, Handel en Scheepvaart. Hiertoe behooren publicisten als: Bartelink, E. J.; Brandon, H. G. ; Bosch Reitz, P.; Comvalius, Th. C.; Dragten, A. A.; Douglass, Chas; Ellis, T. L.; Ferrall, R. A. P. C. O'; Fernandes A. S. J.; Fernandes, D. A.; Focke, mr. H. C. ; Fränkel, J.; Genderen-Rühmann, mevrouw van; Halfhide, dr. J. J.; Hart, W. de; Hering, C. J.; Herrenberg, J. E.; Lichtveld, Lou; Hewitt, W.; Liems, J. A.; May, P. A.; Morpurgo, A. J.; Ommeren, H. J. van; Polak, J. A.; Putscher, A. J.; Romondt, W. H. A. van; Rustwijk, G. G. T.,; Simoons, A. J.; Stuger, J. L.; Vervuurt, A.

De 9de rubriek Boschnegers en Indianen telt 9 schrijvers en wel: Azijnman, S. H.; Biswamitre, C. R.; Comvalius, Th. C.; Einaar, J. F. E.; Focke, mr. H. C.; Lier, W. F. van; Nelson, L. E.; Penard, A. P. en Penard, Thomas E.

De 10de rubriek Muziek telt slechts vier namen en wel die van Amo-van Spall, mevrouw; Comvalius, Th. A. C.; Focke, mr. H. C.; Helstone, J. N. Van Comvalius en mevrouw Amo-van Spall werden muziekstukken uitgegeven. 
Deze droge opsomming van 105 personen kan worden aangevuld met de namen van hen, die wij mochten hebben overgeslagen, en van degenen, die als publicisten bekend zullen worden. Wij willen nog op enkele bijzonderheden wijzen. Ten eerste, dat het aantal romans en geschiedkundige novellen, door Surinamers geschreven, zeer klein is. Johann F. Heymans schreef: De Bastiaan en zijne dochter en Suriname als Ballingsoord, of wat een vrouw vermag. Lou Lichtveld: Zuid-Zuid-West, De Stille Plantage; O' Ferrall: Een beschavingswerk, een sociaal en economisch-politieke studie in romanvorm. J. G. Spalburg schreef Bruine Mina de KotoMissie en pater H. F. Rikken CssR: Codjo, de brandstichter, $M a-$ Kankantree en wellicht nog andere boeken, niet onder zijn naam.

Surinaamsche dichters zijn A. W. Marcus, die tal van rijmbundels uitgaf, G. F. F. Rustwijk en Sonja. Levenbeschrijvingen van Surinamers en Nederlanders vond ik voornamelijk in deSurinaamsche almanakken, zooals die over I. da Costa door R. D. Simons, dr. H. D. Benjamins en dr. G. J. Vanier door A. W. Marcus, H. J. van Ommeren door P. A. May, Julius E. Muller door Harry van Ommeren, August. Kappler door Julius E. Muller, Nicolaas van Meerten door J. R. Thomson, J. F. A. Cateau van Rosevelt door J. E. Morpurgo. Voorts schreef C. P. Rier de biographie van dr. A. F. Gravenbergh 1), C. J. Hering die van mr. H. C. Focke en Comvalius die van C. W. Blijd.

De eenige Surinamer, die hoogleeraar werd, was P. C. Flu, aan wien een eeredoctoraat werd verleend. Eenige der genoemde publicisten schreven in het Engelsch, als J. B. Percival en E. A. van Rossum, Engelsche creolen, die lang in Suriname woonden. Van J. F. Pool, E. J. Bartelink en T. L. Ellis. werden enkele geschriften in het Engelsch vertaald.

Het oudste geschrift in de lijst is dat van mr. H. C. Focke „Verhaal van een togtje naar de landstreek Para in de Kolonie Suriname" (Uit: De Fakkel voor 1830, 33 bldz. gr. $8^{\circ}$. Kol. Boekerij Paramaribo C. 42).

1) In Timehri, Vol VII (third Series) Augustus 1921. Progressive Volume, hebben wij een artikel gepubliceerd The Place of the Creole in the Litterature of Surinam, dat ditzelfde onderwerp in korteren vorm behandelt. Zie ook Suriname van 18 April 1922, no. 31.

2) Zie: Van slaaf tot geneesheer, door ondergeteekende; De W. I. Gids Juli/Aug. 1931 no. 3/4. 